\title{
New 30 kA Power System at Fermilab and its Use for Measuring the Effects of Ripple Current on the Performance of Superconducting High Field Magnets
}

\author{
R. Carcagno, S. Feher, J. Garvey, W. Jaskierny, M. Lamm, A. Makulski, D.F. Orris, H. Pfeffer, M. \\ Tartaglia, J. Tompkins, D. Wolff
}

\begin{abstract}
A new 30 kA, 30 V dc Power System was designed, built, and commissioned at Fermilab for testing Superconducting High Field Magnets. This system has been successfully supporting operations at the Fermilab Magnet Test Facility since April 2002. It is based on six commercial $150 \mathrm{~kW}$ Power Energy Industries power supply modules and the following in-house modules: six $720 \mathrm{~Hz}$ filters, two $15 \mathrm{kA} / 1 \mathrm{kV}$ dc solid-state dump switch, and a $3 \mathrm{MJ} / 30 \mathrm{kA} / 1 \mathrm{kV}$ dc dump resistor. Additional inhouse electronic components were designed and built to provide precise current regulation and distribution of current and current rate of change. An industrial-type Programmable Logic Controller system was used to provide equipment interlocks and monitoring. This paper summarizes studies on the influence of characteristics of this new power system-such as ripple current-on the performance of High Field Superconducting magnets.
\end{abstract}

Index Terms-Superconducting Magnets, High Field, Power Systems, Ripple

\section{INTRODUCTION}

$\mathrm{T}$ HE High Field Magnet Program underway at Fermilab required a new power system to extend the dc current capability at Fermilab's Magnet Test Facility (MTF) to $30 \mathrm{kA}$, $30 \mathrm{~V}$ dc. Other requirements for this system included: $<100$ ppm of full scale absolute current readout accuracy, $<10 \mathrm{ppm}$ of full scale current regulation and stability, and a $3 \mathrm{MJ} / 30 \mathrm{kA}$ energy extraction system. In addition, the system must withstand a maximum voltage of $1000 \mathrm{~V}$ dc during a magnet quench. A system capable of meeting these requirements was designed and built based on existing power components at Fermilab. This system was commissioned in April 2002 and has been successfully supporting the following testing programs at MTF: (1) The $\mathrm{Nb}_{3} \mathrm{Sn}$ High Field Magnet (HFM) program; (2) production testing of LHC Interaction Region Quadrupoles; and (3) production testing of LHC High-

Manuscript received October 5, 2004. This work was supported by the U.S. Department of Energy under contract No. DE-AC02-76CH03000.

All authors are with the Fermi National Accelerator Laboratory, Batavia, IL 60510 USA (R. Carcagno phone: 630-840-3915; fax: 630-840-6724; email: ruben@fnal.gov).
Temperature Superconducting (HTS) Power Leads. Loads connected to the $30 \mathrm{kA}$ system include resistive loads (HTS Power Leads), and superconducting magnets with an inductance range of $35 \mu \mathrm{H}$ to $30 \mathrm{mH}$. Current ramp rates were as fast as $500 \mathrm{~A} / \mathrm{s}$. The maximum HFM magnet quench to date was at $24 \mathrm{kA}$.

The new $30 \mathrm{kA}$ Power System includes several features to provide precise current monitoring and regulation with small ripple. These features will be described in more detail below. Ripple voltage and ripple current characterization results will be presented for different loads. Ripple current at the level observed in this system does not appear to have an adverse effect on the performance of $\mathrm{Nb}_{3} \mathrm{Sn}$ High Field Magnets.

\section{30 KA POWER SYSTEM OVERVIEW}

Fig. 1 shows a block diagram of the $30 \mathrm{kA}$ Power System. The $30 \mathrm{kA}$ bus is shown as solid lines, and electrical signals are shown as dashed lines.

\section{A. Power Supplies}

The system includes six commercial $150 \mathrm{~kW}$ Power Energy Industries (PEI) power supply modules in a master/slave configuration. The Master Power Supply (MPS) provides the Silicon Controlled Rectifiers (SCR) firing signals for all modules. Each power supply has four firing modules with three SCRs each (one per phase), for a total of 12 SCRs. Current regulation is accomplished by an external precise current regulator cascaded to the MPS internal regulator set to "Voltage" mode. Each PEI supply is capable of delivering 5,000 Amps dc at 30 Volts. There is also the option of tapping the supply at higher voltages with the corresponding decrease in maximum current. The system is highly modular, and it can operate with just the master supply or with the master supply plus any combination of slave supplies.

\section{B. $720 \mathrm{~Hz}$ Filters}

To reduce the $720 \mathrm{~Hz}$ ripple of the twelve-pulse, unfiltered PEI supply, a Praeg style filter [1] was designed, built, and added to each supply. Each filter includes a serial $250 \mu \mathrm{H}$ 


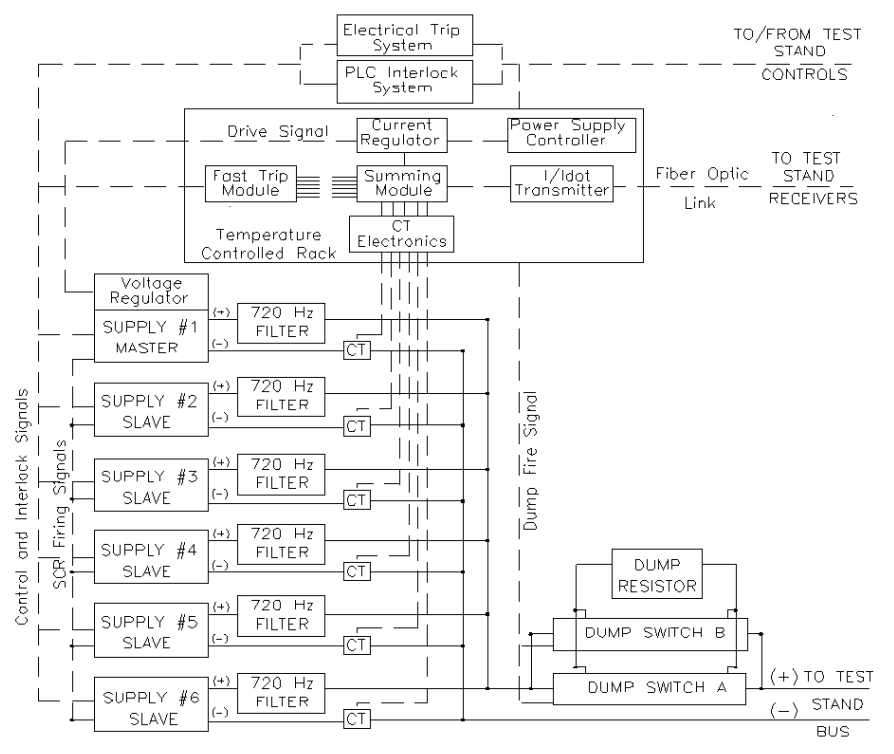

Fig. 1. $30 \mathrm{kA}$ Power System Block Diagram

choke cooled by Low Conductivity Water (LCW), followed by two parallel capacitor banks: a $5.5 \mathrm{mF}$ bank and a $27 \mathrm{mF}$ bank in series with a $200 \mathrm{~m} \Omega$ resistor.

\section{Dump Switch}

Stored energy extraction from a magnet is accomplished by quickly switching a load resistor in series with the bus. Fast switching is accomplished with two $15 \mathrm{kA} 1000 \mathrm{~V}$ de solid state dump switches. These switches were originally made for the SSC project [2], and include six SCRs mounted in watercooled heatsinks. The SCRs continuously carry their share of the rated current, and they are commutated off from stored energy in capacitors. Once the SCRs turn off, the bus current flows through the dump resistor connected in parallel with the dump switches. The original current capacity of the dump switches was $10 \mathrm{kA}$, and they were upgraded to $15 \mathrm{kA}$ by replacing the SCRs with higher rated components. The switch opening time is approximately $25 \mu$ s after detection of a fault or a trip command.

\section{Dump Resistor}

The dump resistor dissipates the stored energy from the magnet after a quench or trip. The resistor was built from aircooled stainless steel elements, and has adjustable taps at 10 , $15,30,60,90$, and $120 \mathrm{~m} \Omega$. It is rated for a maximum current of $30 \mathrm{kA}$, a maximum energy dump of $3 \mathrm{MJ}$, and a maximum voltage across the resistor of $1000 \mathrm{~V}$ dc.

\section{E. Zero-Flux Current Transformer}

The current from each PEI module is measured by a bipolar zero-flux current transformer. The transformer is HITEC system TOPACC type 60-8 bipolar, rated for a current of 6,000 A. DC accuracy error is less than $30 \mathrm{ppm}$, with a temperature coefficient less than $1.5 \mathrm{ppm} / \mathrm{K}$ and drift less than $10 \mathrm{ppm} /$ year.

\section{F. Summing Amplifier}

The output from each zero-flux current transformer is sent to a precision summing amplifier. The summed signal is sent to a precision current regulator and to a VME current transmitter module for distribution and monitoring purposes. The summing amplifier was built with precision resistors with an absolute tolerance of $\pm 0.001 \%$, and an absolute temperature coefficient of $\pm 0.8 \mathrm{ppm} /$ Deg C. Stability tests made on this unit showed less than $2.7 \mathrm{ppm}$ drift in 90 hours.

\section{G. VME Current Transmitter/Receiver modules}

An in-house designed and built VME current transmitter and receiver module is used to distribute via fiber optic cable the current (I) and current rate of change (Idot) data to up to 8 different locations at the Fermilab's Magnet Test Facility. The maximum length of the fiber optic cable is $250 \mathrm{~m}$. The measured accuracy of the current readout is $\pm 10 \mathrm{ppm}$ (integrated over one Power Line Cycle), and the resolution is $\pm 2 \mathrm{ppm}$. The current receiver module accepts the fiber optic signal from the transmitter module and provides six buffered analog I outputs and three analog Idot outputs. The measured analog current value accuracy is $\pm 25 \mathrm{ppm}$, with a resolution of $\pm 2 \mathrm{ppm}$.

\section{H. Current Regulator}

A precision current regulator module was designed and built for this system. The setpoint for this external current regulator is provided by an existing in-house designed and built power supply controller. The output of this regulator is the drive voltage input for the Master Power Supply internal regulator set on "Voltage" mode. Since the $30 \mathrm{kA}$ Power System is intended to be used with a wide range of load inductance and resistance values, the current regulator includes independent settings of load resistance and inductance for tuning the control loop to each particular load. The Resistance setting can be adjusted to $0.1,0.5,1$, and 2 $\mathrm{m} \Omega$. The Inductance setting can be adjusted to $0.05,0.5,2,4$, $10,25,50$, and $100 \mathrm{mH}$. Stability measurements performed at $10 \mathrm{kA}$ show less than $3.5 \mathrm{ppm}$ drift of the current receiver output over a period of 2 hours (a typical magnetic measurement duration.)

\section{Temperature-controlled rack}

To meet the strict current regulation and stability requirements, the following modules are located in a temperature-controlled rack: the HITEC zero-flux current transformer electronics, the summing amplifier module, the current regulator module, and the VME current transmitter module.

\section{J. Personnel Safety}

In adherence to Fermilab's safety regulations, personnel safety is provided by a hardwired interlock chain. This system is called the "Electrical Trip System" (ETS). In the event that any cabinet door or any cover is opened while the system is powered, the ETS system will take three simultaneous actions to protect personnel from electrical hazards: (1) immediately 
initiate a power system phaseback; (2) fire the dump to quickly extract stored energy; and (3) remove the external interlock permissive to each PEI supply.

\section{K. Equipment Safety}

A Programmable Logic Controller (PLC) provides most of the equipment safety interlock and system status monitoring. This system is based on the $1500 \mathrm{~W}$ Helium Refrigerator Control System [3], and includes the series 505 Siemens module for PLC and Input/Output modules, Ethernet communication to the control room, and GE/FANUC FIX32 Human Machine Interface. The PLC monitors the status of various temperature, flow, and other switches and devices. There are 135 physical Input/Output points in this system.

In addition to the PLC system, a module called the "Fast Trip Module" monitors the signals from each zero-flux current transformer to detect a positive or negative current imbalance caused by failures such as a shorted SCR. In the event that an imbalance is detected, this module initiates a phaseback that takes place in less than $16 \mathrm{~ms}$ to avoid damaging more SCRs.

\section{RIPPLE CHARACTERIZATION}

Ripple from the $30 \mathrm{kA}$ Power System is primarily a function of load inductance (L). For instance, the performance of the $720 \mathrm{~Hz}$ filter decreases rapidly for very small inductance loads, and higher current ripple is expected for such loads. Voltage ripple can be directly related to current ripple by considering the load inductance dependence on the current excitation frequency.

Voltage and current ripple measurement results are presented for two magnets from the $\mathrm{Nb}_{3} \mathrm{Sn} \mathrm{HFM}$ program: SR02 $(\mathrm{L}=0.038 \mathrm{mH})$ and HFDA05 $(\mathrm{L}=1.1 \mathrm{mH})$. Inductance values are for warm measurements at $20 \mathrm{~Hz}$. Warm inductance measurements at $1 \mathrm{kHz}$ are a factor of two or more lower. Voltage ripple was measured directly from half-coil voltage taps (whole coil voltage ripple is twice the measured amount.) Current ripple was measured from a current receiver channel. Signals were digitized at 16-bit, $100 \mathrm{kHz}$ with the same system used for HFM Spike Studies [5].

\section{A. Voltage Ripple}

The voltage ripple was measured at several excitation currents. Fig. 2 shows typical voltage ripple measurements for SR02 and HFDA05 at $12 \mathrm{kA}$. Fig. 3 shows a Fast Fourier Transform (FFT) of the signals from Fig. 2. In addition to the expected $720 \mathrm{~Hz}$ component, there are several substantial subharmonic ripple components at 60,120, 180, 240, and 360 Hz. These subharmonic components are caused by imbalances such as firing circuit imbalance, line imbalance, and transformer imbalance. As shown, the larger inductance magnet HFDA05 has a much larger voltage ripple. The levels of each subharmonic is a function of excitation current and overall the voltage has a minimum at approximately $7000 \mathrm{~A}$.

\section{B. Current Ripple}

Fig. 4 shows the current ripple corresponding to the voltage ripple of Fig. 2. The largest ripple corresponds to the lower inductance magnet (SR02), which shows approximately $20 \mathrm{~A}$ peak-to-peak current ripple. Frequency components of the current ripple are similar to the frequency components of the voltage ripple (Fig. 3).

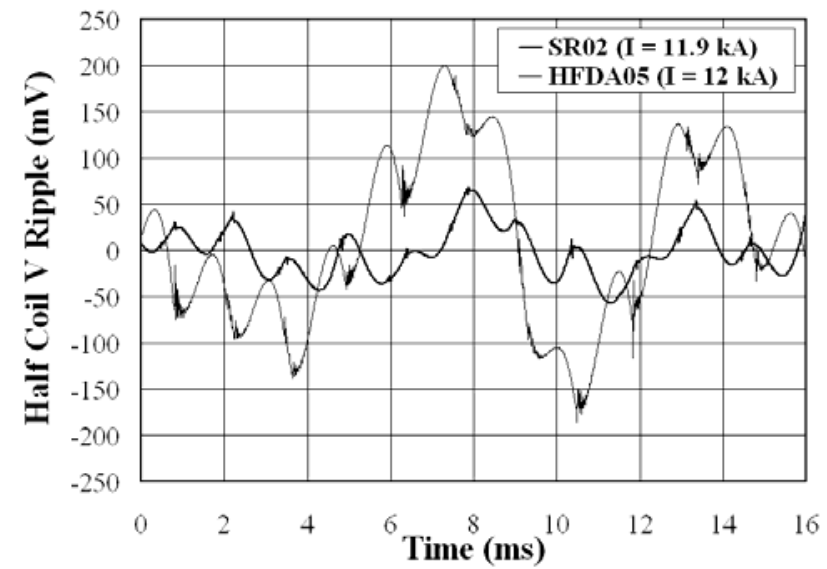

Fig. 2. Half Coil voltage ripple measurements for SR02 $(\mathrm{L}=0.038 \mathrm{mH})$ and $\operatorname{HFDA05}(\mathrm{L}=1.1 \mathrm{mH})$

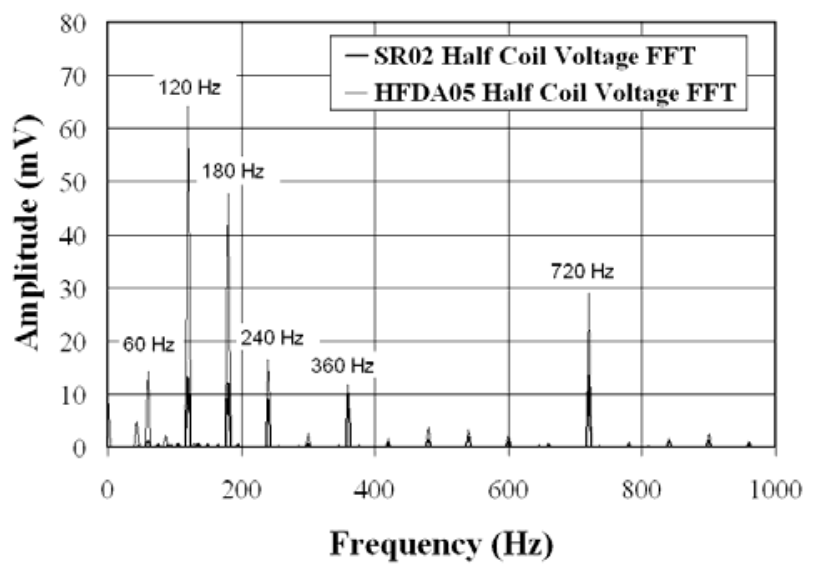

Fig. 3. Half Coil voltage ripple FFT for SR02 and HFDA05

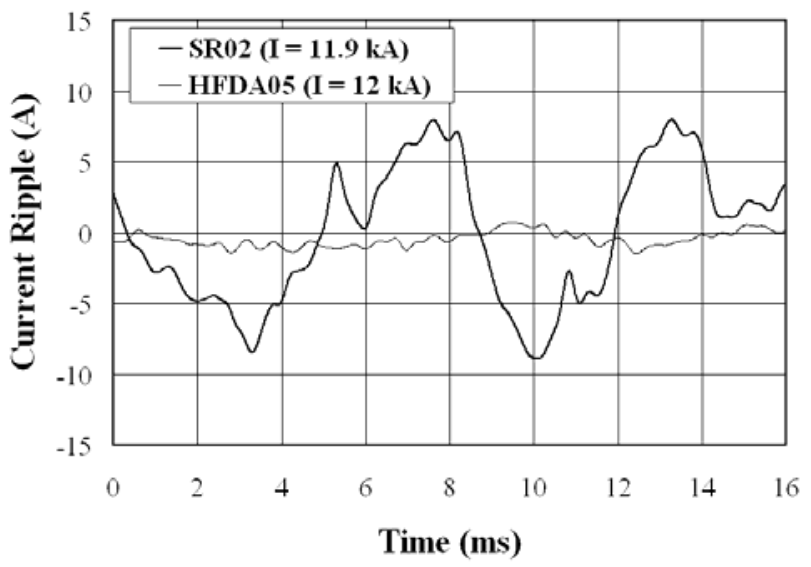

Fig. 4. Current ripple measurements for SR02 and HFDA05 


\section{RIPPLE AND HFM PERFORMANCE}

A question often asked is whether power supply ripple may affect the performance of $\mathrm{Nb}_{3} \mathrm{Sn}$ High Field Magnets. The $\mathrm{Nb}_{3} \mathrm{Sn}$ reaction process can facilitate low interstrand resistance. High frequency sub harmonics can then generate Eddy currents in the conductor leading to AC loss heat generation, which in turn could result in a reduction in the quench current.

Several magnets from the $\mathrm{Nb}_{3} \mathrm{Sn}$ HFM program have been tested using this $30 \mathrm{kA}$ power system [6], [7]. SR01 and SR02 are magnets with the same geometry and inductance but have $\mathrm{Nb}_{3} \mathrm{Sn}$ conductor made from difference manufacturing process. HFDA05 (HFDB02) have the same cable as SR01 (SR02) respectively but have a different coil geometry and larger inductance. SR01 and HFDA05 were able to reach their critical current under the ripple conditions presented in Section III. For HFM magnets that did not reach their critical current (e.g. SR02 and HFDB02), conductor instabilities appear to be the reason for this performance shortcoming [4].

To investigate whether power supply ripple played a role in the quench performance, further quench tests were performed on HFDB02 and HFDA05. First, HFDB02 was powered in series with a paralleled connection of two Fermilab main ring dipoles. The added inductive load to the system reduced the voltage and current ripple on HFDB02 by approximately a factor of five. No improvement was observed in quench performance. Next, HFDA05 was tested under extreme ripple conditions by disabling the $720 \mathrm{~Hz}$ filter for each PEI supply. This was accomplished by disconnecting the capacitor bank from the bus. Fig. 5 compares the voltage ripple of HFDA05 with and without the $720 \mathrm{~Hz}$ filter. The voltage ripple without the filter is approximately five times higher than with the filter. When the magnet was ramped to quench with the filter disabled, it again quenched at its critical current. This test was performed at two different temperatures, and Fig. 6 compares the quench current with the filter disabled with other quenches at various temperatures with the filter enabled. As shown, the performance of HFDA05 under extreme ripple conditions is no different than under normal ripple conditions, following

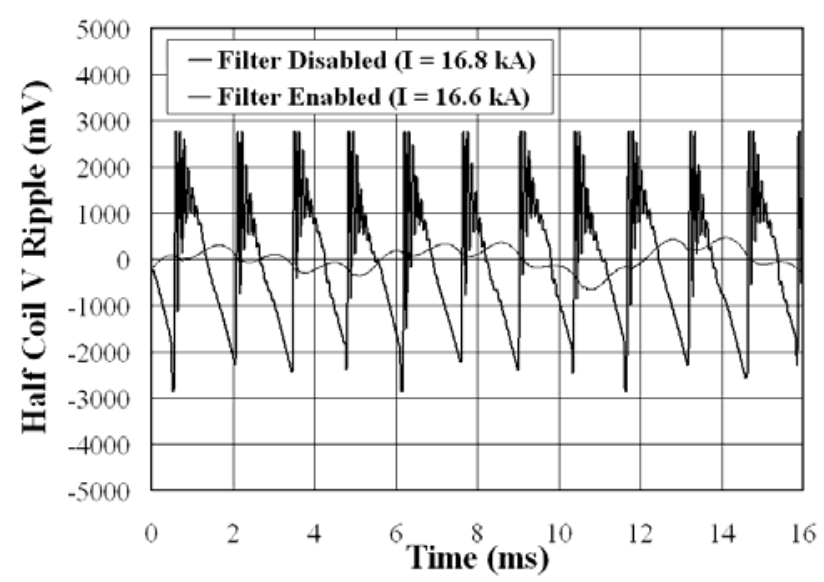

Fig. 5. HFDA05 Voltage ripple with and without the $720 \mathrm{~Hz}$ filter (The filter disabled signal briefly reached input channel saturation in the positive peaks.)

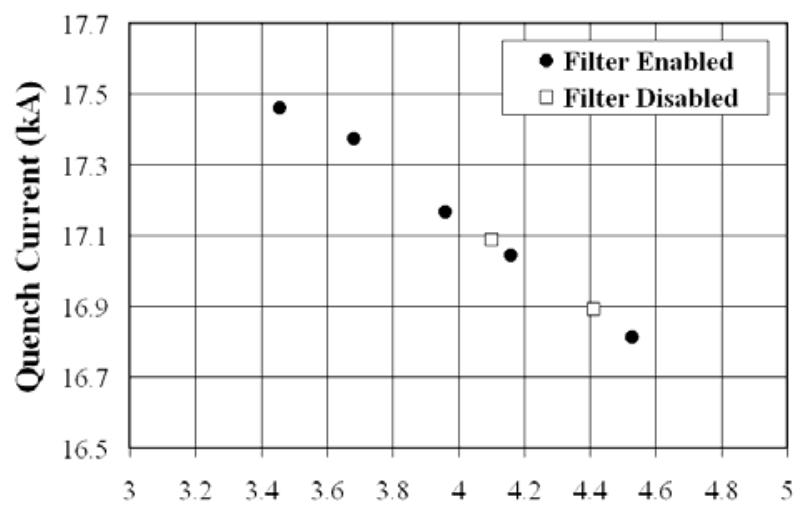

Temperature (K)

Fig. 6. HFDA05 Quench Current vs. temperature with and without $720 \mathrm{~Hz}$ filter.

the same temperature dependence as expected for a magnet that has reached its critical current. These two results suggest that the power supply ripple at the level produced by the $30 \mathrm{kA}$ Power System does not have an adverse effect on the performance of High Field Magnets.

\section{CONCLUSION}

Voltage and current ripple characteristics of a new $30 \mathrm{kA}$, $30 \mathrm{~V}$ dc power system at the Fermilab's Magnet Test Facility were measured for different inductance loads. The quench performance of $\mathrm{Nb}_{3} \mathrm{Sn}$ High Field Magnets was analyzed under different ripple conditions and it appears that power supply ripple does not have an adverse effect on the performance of these magnets.

\section{ACKNOWLEDGMENT}

We wish to acknowledge the contributions of Julius Lentz to the design, fabrication and test of several new components required for the $30 \mathrm{kA}$ Power System.

\section{REFERENCES}

[1] W. Praeg, "A High Current Low Pass Filter for Magnet Power Supplies," IEEE Trans. on Industrial Electronics and Control Instrumentation, vol. IECI-17, no. 1, pp. 16-22, February 1970

[2] A. Visser, "A 10,000 A 1000 VDC Solid State Dump Switch," $4^{\text {th }}$ European Conference on Power Electronics, September 3-6, 1991, Florence, Italy.

[3] R. Carcagno and R. Rabehl, "Controls Upgrade of the Fermilab Magnet Test Facility 1500 W Helium Refrigerator," Advances in Cryogenic Engineering, vol. 45, pp. 1795-1802, Plenum Press, New York, (2000)

[4] S. Feher et al., "Sudden Flux Change Studies in High Field Superconducting Accelerator Magnets", Submitted to this conference.

[5] D. Orris et al., "Spike Detection: A System for Detecting Rapid Superconducting Magnet Flux Changes", Submitted to this conference

[6] A.V. Zlobin et al., "Development and Test of Nb3Sn Cosine $(\Theta)$ Dipoles based on PIT strands", Submitted to this conference.

[7] G. Ambrosio et al., "Fabrication and Test of a Racetrack Magnet Using Pre-Reacted Nb3Sn Cable," IEEE Trans. Appl. Supercond., vol. 13, no. 2, pp. 1284-1287 